\title{
O SAMBA DE UMA NOTA SÓ NO PENSAMENTO DE SLAVOJ ZIZEK
}

Fernando Facó de Assis Fonseca ${ }^{1}$

Resumo: O presente texto aborda tema da liberdade no pensamento de Slavoj Zizek. Defende-se que, por trás do mosaico que se apresenta o pensamento do filósofo, tratando dos mais diversos temas sob as mais variadas teorias filosóficas, a preocupação de Zizek é uma só, a saber, como (re)pensar a questão da liberdade humana, conduzindo ao extremo o aspecto da finitude pós-reviravolta copernicana. Em outros termos, a proposta é basicamente radicalizar o tema da liberdade em uma base materialista, levando ao limite o esquema transcendental de Kant. Para isso, propõe-se debater o tema em quatro linhas discursivas: ciência, ontologia, subjetividade e política emancipatória.

Palavras-chave: Liberdade. Finitude. Materialismo dialético.

Abstract: The present text addresses the theme of freedom in the thought of Slavoj Zizek. It is argued that, behind the mosaic of the philosopher's thought, dealing with the most diverse subjects under the most varied philosophical theories, Zizek's concern is only one, namely how to (re) think the question of human freedom, leading to the extreme the aspect of Copernican post-twisting finitude. In other words, the proposal is basically to radicalize the theme of freedom on a materialistic basis, pushing Kant's transcendental scheme to the limit. For this, it is proposed to discuss the theme in four discursive lines: science, ontology, subjectivity and emancipatory politics.

Key words: Freedom. Finitude. Dialectical Materialism.

\section{Samba de uma nota só...}

Tornou-se lugar-comum entre os críticos de Zizek ressaltar - não raro com um toque de sarcasmo - a excessiva prolixidade de seus escritos. Basta ver, por exemplo, a crítica de John Gray (2013) endereçada a ele em As visões violentas de Zizek, onde ele diz: "interpretar Zizek nesta questão ou em qualquer outra tem suas dificuldades. Primeiro existe a sua prolixidade excessiva, a torrente de textos que ninguém poderia ler na sua totalidade, mesmo porque ela nunca para de jorrar...”. O fato é que o esloveno provoca uma estupefação geral na comunidade de leitores quando se trata de sua - para utilizar esses termos - incontinência intelectual, manifestada tanto no volume excessivo de sua produção bibliográfica, quanto na vasta e diversificada área temática que ele aborda num só fôlego. Digamos que, numa perspectiva horizontal, Zizek é capaz de articular, numa fusão impressionante, desde assuntos de caráter mais laico, como cultura popular, ciência e política, até o sumo da metafísica e da teologia cristã, saltando de um para o outro com extrema destreza. E para dificultar ainda mais, todos esses tópicos são sempre atravessados verticalmente por duas matrizes teóricas fundamentais: a dialética

\footnotetext{
Doutor em Educação - FACED - na área de filosofia, política e educação. Possui mestrado em Filosofia pelo programa Erasmus Mundus Europhilosophie (2010) nas respectivas Universidades: Universidade de Luxemburgo, Universidade Charles de Praga e pela Universidade de Toulouse Le Mirail. Possui também mestrado em Filosofia pela Universidade Federal do Ceará (2008). É formado em Psicologia pelo Centro Universitário de Brasília. Áreas de atuação: filosofia contemporânea, psicanálise, política e ética.
} 
hegeliana e a psicanálise lacaniana. Por esse ângulo, é inteiramente lícito que concedamos um crédito aos críticos de Zizek: diante dessa (con)fusão teórica, realmente não é fácil alcançar o cerne de seu pensamento e, com isso, desenvolver uma análise mais profunda a seu respeito.

Mas e se, por outro lado, por trás desse mosaico de superfície, residir uma estrutura compacta e monocromática que só uma leitura atenta e persistente pode revelar? É assim que todo comentador e estudioso de Zizek deve proceder: não simplesmente em se deixar fascinar pelo espetáculo grandiloquente de sua habilidade retórica, mas ir em busca do nó sintomático de seu pensamento, daquilo que Freud chamou de Widerholungswang, a compulsão à repetição. O fato é que Zizek, como todo grande pensador, possui um núcleo duro, uma base monossilábica e repetitiva que ecoa em toda extensão de seu pensamento, aquela ideia insistente e obsessiva que condensa a exuberante variação discursiva na monotonia de um tema único. Por isso que é preciso ler Zizek como se lê um clássico, isto é, saber lê-lo sob o mesmo cuidado pontual com que se lê um Heidegger, ou até mesmo Kant. Nesse sentido, para utilizarmos uma metáfora apropriada de nossa cultura do samba, em vez de um samba do criolo doido, a cadência do pensamento de Zizek se aproxima muito mais do delicado samba de uma nota só, de Tom Jobim e Newton Mendonça. Então, a pergunta é: que única nota é essa, qual é o compasso desse samba, cuja base é uma só? A hipótese central do presente texto é que o pensamento de Zizek é todo fundado sobre o tema da liberdade e emancipação humana. Ou seja, nossa aposta é que toda a obra de Zizek é uma tentativa de responder a uma só questão: como é possível hoje (re)pensar o tema da liberdade humana?

Nesse sentido, Zizek se alinha à tradição da Aufklärung, para quem a pergunta sobre a emancipação humana era, por definição, a pergunta filosófica primordial. Ao menos foi assim que Kant a interpretou:

Esclarecimento [Aufklärung] é a saída do homem de sua menoridade, da qual ele próprio é culpado. A menoridade é a incapacidade de fazer uso de seu entendimento sem a direção de outro indivíduo. O homem é o próprio culpado dessa menoridade se a causa dela não se encontra na falta de entendimento, mas na falta de decisão e coragem de servir-se de si mesmo sem a direção de outrem. Sapere aude! Tem a coragem de fazer uso de teu próprio entendimento, tal é o lema do esclarecimento [Aufklärung] (KANT, 2005, p. 63).

Sem tirar nem pôr, é exatamente disso que se trata o pensamento de Zizek:

\begin{tabular}{|l|l|l|l|l|}
\hline Qevista Dialectus & Ano 3 & n. 9 & Setembro - Dezembro 2016 & p. 26 - 45
\end{tabular}


pensar a coragem de servir-se autonomamente de si mesmo, sem a direção de outrem, sem a garantia de um fiador externo para nossas ações. Como Kant (2005) deixa claro, a condição de menoridade do homem não é um mero problema de ignorância. Longe disso, ela expressa uma maneira ilegítima de nos apoiarmos em alguma exterioridade, numa lei heteronômica, para que, assim, não tenhamos de lidar com a radicalidade de nossa finitude humana. Mas no que consiste a liberdade para Kant?

Em sua Crítica da Razão Prática, Kant (2011) define a liberdade como um factum da razão:

Pode-se denominar a consciência desta lei fundamental um factum da razão,
porque não se pode sutilmente inferi-la de dados antecedentes da razão, por
exemplo, da consciência da liberdade (pois esta consciência não nos é dada
precisamente), mas porque ela se impõe por si mesma a nós como uma
proposição sintética a priori, que não é fundada sobre nenhuma intuição, seja
pura ou empírica, se bem que ela seria analítica se se pressupusesse a
liberdade da vontade, para o que porém se requereria como conceito positivo
uma intuição intelectual, que aqui de modo algum se pode admitir. Contudo,
para considerar esta lei como inequivocamente dada, precisa-se observar que
ela não é nenhum fato empírico mas o único factum da razão pura, que deste
modo se proclama como originariamente legislativa (KANT, 2011, p. 52-53:
grifo nosso).

Em resumo, segundo Kant (2011), a liberdade consiste na irrupção da própria razão, que não está sujeita a nenhuma intuição, nem pura nem empírica ${ }^{2}$. Essa definição é crucial para Zizek: segundo ele, isso elimina a hipótese de uma referência cognitivista da liberdade kantiana, ou seja, de que é possível encontrar o fundamento da liberdade na própria atividade reflexiva do sujeito finito. Zizek (2012, p.119) compreende esse factum da razão como sendo, em última análise, "inexplicável, irracional, inimputável”, portanto, impossível de ser fundamentado enquanto princípio racional, segundo uma atividade puramente cognitiva por cujo meio poderíamos reflexivamente alcançar os fundamentos de nossa própria liberdade. Mas isso não quer dizer que a liberdade seja ela mesma irracional; a proposta aqui é que ela é racional, mas não hipotética. Isso significa que, em sua segunda Crítica, Kant (2011) concebe a liberdade como sendo o próprio fundamento da razão, a abertura primordial da atividade reflexiva. E como tal, sendo ela factum ou abertura, torna-se, portanto, irredutível à própria esfera do Entendimento. Liberdade é, pois, um pressuposto estruturalmente necessário para a atividade reflexiva. Tiramos então uma conclusão necessária: não é que o sujeito seja

\footnotetext{
${ }^{2}$ Como bem expressa Schneewind (2005) sobre o assunto: “A autonomia, como a via Kant, requer uma liberdade contracausal; e ele acreditava que, na experiência única do dever moral, nós 'recebemos' um 'fato da razão' que nos mostra inquestionavelmente que possuímos essa liberdade como membros de um reino numenal.” (p.29).
}

\begin{tabular}{|l|l|l|l|l|}
\hline Q Rovista Dialectus & Ano 3 & n. 9 & Setembro - Dezembro 2016 & p. $26-45$ \\
\hline
\end{tabular}


livre porque é racional, mas o inverso: ele é racional porque é livre, isto é, a liberdade vem em primeiro lugar. Consequentemente, não podemos jamais supor um fundamento externo para a liberdade; a liberdade é sempre causa sui, fundamento de si mesma. A liberdade constitui, nessa perspectiva, a verdadeira "essência" do ser humano.

Mas, por mais brilhante que seja essa torção kantiana da liberdade como a priori da razão, isso não deixa de gerar algumas lacunas filosóficas. Por exemplo: se a liberdade é o fundamento da própria razão, aquilo que não pode ser apreendida (ou fundamentada) reflexivamente - até porque é ela a base do próprio campo do pensamento reflexivo - então, como seria possível pensá-la em sua condição positiva, e não apenas como o negativo do próprio pensamento, isto é, como um pressuposto necessário, mas não conhecido? E ainda: como reconhecer um ato puro de liberdade em nossa própria realidade fenomenal, já que ela é irredutível às formas a priori da intuição sensível? Pensar a condição da liberdade humana nesse sentido estrito não é uma tarefa fácil. Somos inclusive tentados a dizer que, em vista disso, a dificuldade de ser verdadeiramente kantiano é difícil até para o próprio Kant. Embora a questão tenha sido posta de maneira exemplar pelo filósofo, isso não significa que ela tenha sido radicalizada por ele. Isto é, Kant estabeleceu as premissas, mas o caminho ainda teria de ser percorrido por outros. E quem são esses outros, afinal? Para Zizek não resta dúvidas, trata-se inequivocamente de Hegel e Lacan. O maior desafio de Zizek é, portanto, a partir de uma fina articulação entre a dialética hegeliana e a psicanálise lacaniana, levar a cabo esse projeto de Kant, isto é, pensar sem retóricas o abismo da liberdade humana no seu limite extremo.

\section{Ciência e Liberdade}

Seria, portanto, correto dizer que o esforço teórico de Zizek não é superar, mas sim recuperar a intuição originária de Kant, mantendo-se, desse modo, firme aos ideais iluministas de autonomia e emancipação humana. Mas é preciso reconhecer que, antes dele, outros investiram fortemente nessa empreitada, como é o caso mais conhecido de todos: Jürgen Habermas e sua pragmática formal. Nesse sentido, poderíamos afirmar que, em pelo menos num ponto, Habermas e Zizek estão de acordo: ambos rejeitam de modo peremptório a tese de que a modernidade é um projeto fracassado, ultrapassado. Para eles, não há como escapar das coordenadas estruturais estabelecidas na e pela 
modernidade. A tarefa da filosofia, em última instância, ainda continua sendo a mesma daquele período, mesmo que a tendência do pensamento contemporâneo aponte na direção oposta. Nesse sentido, Habermas e Zizek caminham na direção contrária à moda pós-moderna, procurando, cada um a seu modo, efetivar o potencial interno do pensamento moderno, que ainda permanece latente nos dias de hoje.

Contudo, o ponto em que eles coincidem, é o ponto em que eles divergem. Zizek encara o projeto da modernidade de modo radicalmente diverso do de Habermas. A diferença entre eles pode ser posta da seguinte forma: enquanto Habermas procura adequar o pensamento kantiano às exigências de uma realidade secularizada e pósmetafísica, Zizek, ao contrário, visa demonstrar que a radicalização de um pensamento pós-metafísico já está presente no próprio Kant. Zizek é aqui mais kantiano que Habermas: para Zizek (2008), a estratégia habermasiana do deslocamento da subjetividade para o campo da práxis linguística serve apenas para ocultar o núcleo traumático do pensamento de Kant. Em outras palavras, a transferência da centralidade da razão subjetiva para uma dimensão intersubjetiva - o espaço simbólico onde os indivíduos participam ativamente de uma acareação racional entre si - consiste, para Zizek, numa forma ilegítima de domesticar o efeito antagônico que a ideia de sujeito kantiano acarretou na modernidade. Portanto, para Zizek (2008), só podemos avançar sobre Kant e, assim, radicalizar a verdadeira condição pós-metafísica da modernidade, se insistirmos na intuição originária do próprio Kant, qual seja, o núcleo irredutível do sujeito moderno.

Para deixar clara a diferença entre as duas posturas, tomemos como exemplo a polêmica questão da biogenética. Hoje, mais do que nunca, somos constantemente assombrados com a possibilidade de uma total decodificação de nosso código genético, e o que muito provavelmente desencadearia uma manipulação desenfreada de nossa própria natureza humana. Dito de outro modo, a possibilidade de uma total autotransparência de nossa infraestrutura genética corresponde à possibilidade de uma poderosa instrumentalização da própria base ontológica de nossa espécie. Ora, para vislumbrar os efeitos devastadores que isso poderia ocasionar, basta se perguntar sobre as condições que uma sociedade teria para cultivar os ideais de liberdade e autonomia moral quando indivíduos da mesma espécie passarem a ser geneticamente manipulados e programados uns pelos outros. Nesse sentido, a biogenética constitui uma ameaça direta à integridade do ser humano enquanto ser livre e autônomo. O cenário é 
perturbador em todos os aspectos: na "menos pior" das hipóteses, por assim dizer, uma intervenção direta em nossos genes produziria uma série de mutações físicas e psicológicas que poderiam suscitar um profundo impacto nas relações sociais existentes (como divisões de classes fundadas na diferença biológica, indivíduos superpotencializados por métodos artificiais etc.); e na pior delas, uma tecnificação dessa magnitude no cerne da própria natureza humana seria uma ameaça direta àquilo que Kant (2005) chamou de uso da razão pública, ou seja, a capacidade de o indivíduo se servir livremente do exercício de sua razão universal. Se a hipótese materialistapositivista - de que nossa base orgânica é o substrato de nossa vida espiritual - estiver correta, então, uma vez acessada a linguagem padrão de nossa natureza humana, tudo o que pensamos, desejamos e sentimos serão passíveis de manipulação. Se isso acontecer - ou quando acontecer -, como será então possível discernir o exercício da razão pública da razão privada? Ou seja, o que de fato garantiria que o exercício de nossa razão seja fundado em bases universais, e não manipulado por agências de controle? $\mathrm{O}$ problema é iminente e preocupante, e a saída habermasiana para o dilema é a mais conservadora possível: segundo Habermas (2010), é preciso aplicar uma intervenção normativa que limite o progresso ininterrupto da ciência. $\mathrm{O}$ autor visa com isso proteger o mínimo de contingência que sustenta nossa natureza humana e, assim, salvaguardar o estatuto de nossa liberdade. Ou seja, é como se nossa liberdade dependesse estritamente de uma espécie de ignorância abençoada, que deve ser preservada longe do alcance da ciência. Na medida em que essa contingência, o puro acaso que define nossa espécie humana, for trazida à luz sob a forma de código genético, então ideias como liberdade e autonomia estariam completamente comprometidas.

Zizek (2011a), por sua vez, aposta no sentido inverso: segundo ele, somente se levarmos as pesquisas científicas ao seu paroxismo é que haverá a possibilidade de se repensar os princípios de liberdade e autonomia humana. A postura de Zizek aqui é uma postura verdadeiramente secular e progressista, em contraste com o conservadorismo de Habermas. Para o esloveno, na ânsia de superar Kant, Habermas tropeçou no mesmo impasse de seu formalismo: o que impede Habermas de ir às vias de fato, no que tange às pesquisas científicas mais recentes, é o mesmo princípio formal que impediu Kant de levar sua reviravolta copernicana às consequências ontológicas. Em outras palavras, o mínimo de contingência que Habermas procura preservar no ideal de natureza humana para salvar a autonomia e a liberdade é o correlato formal do princípio de

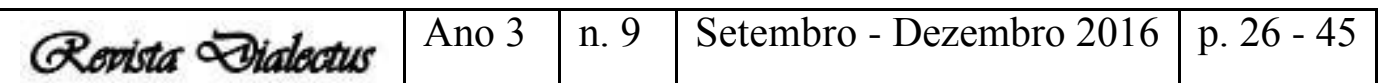


incognoscibilidade que Kant teve de preservar para salvar seu edifício teórico. E essa incognoscibilidade é, com efeito, a condição de possibilidade de nossa autonomia moral. Como escreve Zizek (2014): "recordemos que Kant pensava que nossa ignorância da realidade numenal era uma condição de nossa capacidade de agir eticamente: se conhecêssemos as Coisas em si mesmas, agiríamos como autômatos" (p. 562, n. 28). Somos, desse modo, tentados a resumir numa só fórmula a estrutura específica do formalismo transcendental - que vai de Kant a Habermas: a condição de impossibilidade (de uma autotransparência absoluta) consiste na própria condição de possibilidade (da liberdade). Em outras palavras, só podemos conceber nossa liberdade na medida em que a forma específica do modelo transcendental, fundado na finitude humana, impede nosso acesso direto ao fundamento ontológico de nosso ser. Zizek localiza na Crítica da Razão Prática o ponto exato onde Kant revela o que aconteceria se por acaso pudéssemos atravessar o limite transcendental de nossa finitude e ter acesso ao domínio numênico, à Ding an Sich:

Em vez do conflito que agora a disposição moral tem de sustentar com as inclinações e no qual, depois de algumas derrotas, contudo pode conquistarse aos poucos uma fortaleza moral de alma, Deus e a eternidade, com sua terrível majestade, encontrar-se-iam incessantemente ante os olhos (...) assim, a maioria das ações acorreria por medo, poucas por esperança e nenhuma por dever, porém não existiria um valor moral das ações, do qual, aos olhos da suma sabedoria, depende unicamente o valor da pessoa e mesmo o valor do mundo. Portanto a conduta do homem, enquanto a sua natureza continuasse sendo como atualmente é, seria convertida em um simples mecanismo, em que, como no jogo de bonecos, tudo gesticularia bem, mas nas figuras não se encontraria, contudo, vida alguma (KANT, 2011, p. 235).

Mesmo que do ponto de vista fenomênico tudo permaneça inalterável, um acesso direto ao reino numênico traria, em última instância, consequências drásticas para a liberdade do homem: "enquanto sua natureza continuasse sendo como atualmente é, seria convertida em um simples mecanismo, em que como no jogo de bonecos, tudo gesticularia bem, mas nas figuras não se encontraria, contudo, vida alguma" (KANT, 2011, p. 235). Facilmente poderíamos transferir essa mesma preocupação kantiana para o modo como Habermas se posiciona em relação aos avanços da biogenética: o mapeamento completo do genoma humano não corresponderia, em última análise, a esse acesso direto à dimensão numenal do qual fala Kant, cujo efeito imediato seria justamente a perda de nossa liberdade/espontaneidade, nos convertendo, desse modo, em simples marionetes, ou para utilizar um termo mais corrente, em máquinas pensantes? O problema é que para Zizek (2011a) a mera possibilidade dessa ameaça já

\begin{tabular}{|l|l|l|l|l|}
\hline Qevista Dialectus & Ano 3 & n. 9 & Setembro - Dezembro 2016 & p. 26 - 45 \\
\hline
\end{tabular}


solapa os fundamentos da liberdade humana em sua forma padrão e conservadora: uma vez que temos consciência da possibilidade de que nossa natureza humana pode ser geneticamente manipulável, essa possibilidade já começa a funcionar de maneira efetiva, já produz efeitos reais. É como se, de uma forma ou de outra, o segredo fosse revelado: não possuímos uma natureza humana, somos sempre-já potencialmente instrumentalizáveis. Ou seja, não é mais possível apostar num substrato orgânico intangível em cuja base repousa a essência de nossa liberdade. Logo, não adianta, segundo Zizek (2011a), limitar os avanços da ciência, a máscara já caiu! Nesse sentido, cumpre, portanto, incluir essa possibilidade como sendo já efetiva, e a tarefa a partir de então passa a ser fundamentalmente repensar o estatuto da liberdade humana a partir $d a$ - e não contra $a$ - ciência.

Ora, mas se a origem dessa limitação epistemológica não está em Habermas, e sim em Kant, então a solução também deve ser buscada em Kant. Assim, só é possível encontrar a saída radicalizando o pensamento de Kant, ou melhor, buscando o que há em Kant que é mais do que Kant ele mesmo. Ou seja, diferentemente de Habermas, devemos retornar a Kant para resgatar não seu formalismo metodológico, mas recuperar o núcleo materialista do seu pensamento - algo que estava lá desde sempre, embora ele mesmo não tenha percebido. Assim, se Habermas, ao tentar superar Kant, foi vítima da cegueira de seu formalismo, nos resta então atravessar o puro formalismo da filosofia transcendental executando o passo que o próprio Kant recusou a dar. Em suma, é preciso realizar o salto ontológico inerente à própria guinada transcendental, e, assim, "atravessar" os limites da finitude humana para, enfim, pensar a verdadeira dimensão da liberdade humana.

\section{Ontologia e Liberdade}

Pensar Kant mais do que Kant ele mesmo significa, para Zizek, encontrar o núcleo ontológico do pensamento de Kant, mas sem, é claro, regredir ao dogmatismo pré-crítico. Em outras palavras, trata-se de fazer avançar o projeto crítico kantiano e, imanente a ele, extrair o excesso ontológico que o próprio Kant se recusou a pensar. Nesse sentido, no âmbito da filosofia, somente Hegel foi capaz dessa empreitada. O mote da dialética materialista de Zizek é, portanto, pensar Hegel como sendo mais kantiano que o próprio Kant o foi. Zizek procura com isso suplantar definitivamente a

\begin{tabular}{|c|c|c|c|}
\hline Q Rovista Dialactus & Ano 3 & n. 9 & Setembro - Dezembro 2016 \\
\hline
\end{tabular}


visão ortodoxa de um idealismo absoluto de Hegel. Segundo essa leitura conservadora, Hegel surge como uma espécie de monstro panlogista que devora e mortifica a viva substância do particular na reconciliação final do Saber Absoluto, ou seja, aquele que foi capaz de selar a lacuna epistemológica deixada aberta por Kant, restabelecendo o Absoluto como a comunhão ontológica primordial, como a unidade capaz de reunir num todo harmonioso o impasse da relação sujeito/objeto. Não obstante, a leitura de Zizek vai numa direção radicalmente oposta: o grande mérito de Hegel não consistiu na superação da lacuna epistemológica kantiana, mas justamente em tê-la radicalizado em sua condição propriamente ontológica. Isso quer dizer que, se Kant localizou o cerne da finitude nos limites transcendentais da razão humana, não é, de modo algum, o objetivo de Hegel extrapolar esses limites e alcançar uma realidade em si, ontologicamente constituída, mas "simplesmente" em deslocar a lacuna da finitude para a dimensão ontológica, ou seja, conceber a própria realidade como sendo ontologicamente incompleta, finita.

Para Zizek (2008), o nome apropriado para essa lacuna ontológica é paralaxe. Ele entende por paralaxe "o deslocamento aparente de um objeto (mudança de sua posição em relação ao fundo) causado pela mudança do ponto de observação que permite uma nova linha de visão" (ZIZEK, 2008, p. 28). Em outras palavras, paralaxe consiste não na mudança espacial, mas na mudança "aparente" de posição de um mesmo objeto realizada a partir de uma nova linha de visão. Em sentido filosófico, essa ideia nos permite pensar em uma não coincidência do objeto para com ele mesmo, isto é, uma tensão inerente, ou uma diferença mínima na própria identidade do objeto. Para melhor esclarecer essa ideia, devemos levar em consideração as antinomias da razão pura de Kant. Segundo o filósofo, se seguirmos cegamente o fio da razão pura, somos levados inevitavelmente a um impasse irredutível, no qual, de um lado, uma tese apresenta as pretensões da razão de construir uma totalidade universal, enquanto de outro, a antítese apresenta, do ponto de vista cético, a impossibilidade constitutiva dessa grandeza universal (KANT, 2010). O grande mérito de Kant, nesse sentido, foi ter se recusado categoricamente a resolver esse impasse. Para ele, o preço a pagar por nossa finitude consiste justamente em manter essas duas dimensões coexistindo lado a lado, sem se confundirem ou se tocarem. É claro que Kant não visa com isso afirmar a nossa impossibilidade intrínseca do conhecimento, mas o exato oposto: o conhecimento só é possível se conseguirmos submeter os limites de nossa razão aos dados fornecidos pela

\begin{tabular}{|c|c|c|c|}
\hline Q Rovista Dialactus & Ano 3 & n. 9 & Setembro - Dezembro 2016 \\
\hline
\end{tabular}


experiência. Assim, a saída kantiana para o impasse constitutivo da razão pura consiste numa espécie de controle rigoroso dos limites de nossa própria finitude, de maneira que as antinomias representam nada mais que uma falha ou descuido desse complexo mecanismo de ajuste entre a dimensão da razão pura e a dimensão da realidade fenomênica, ou seja, elas surgem exatamente quando tendemos a extrapolar os limites da própria realidade empírica e alcançar, através de uma pura relação de causalidade, os princípios cosmológicos universais. Nesse sentido, devemos afirmar sem medo que, uma vez que a atividade do conhecimento em Kant depende unicamente da boa ou da má aplicação de nossas categorias aos dados da realidade, então estamos lidando com uma visão essencialmente instrumentalista do uso das categorias.

Não seria equivocado dizer que o conceito de paralaxe é um conceito fundamentalmente kantiano, uma vez que podemos entender as antinomias da razão pura como uma espécie de visão em paralaxe, ou seja, como um deslocamento aparente do mesmo objeto ocasionado por uma mudança de perspectiva ${ }^{3}$. Mas o ponto é que sua concepção instrumentalista do uso das categorias - seu uso correto ou incorreto - induz Kant a tratar as antinomias como um mero desvio no curso da objetividade do conhecimento. E é aqui que Hegel entra em cena. Segundo Zizek (2012), Hegel pensa as antinomias não a partir da nossa finitude humana, mas como antagonismo inerente à própria realidade. Ou seja, as antinomias não são os paradoxos da razão subjetiva provocados por uma falha ou descuido na aplicação das categorias à experiência sensível; as antinomias, para Hegel $(2005, \S 48)$, possuem um estatuto propriamente ontológico, isto é, elas dizem respeito à falha ou incompletude da própria realidade. Em suma, em Hegel, é a própria realidade que é contraditória em si mesma. Nesse sentido, Hegel alcança a Coisa-em-si kantiana não ultrapassando a lacuna que nos separa do reino numênico, mas considerando essa lacuna como sendo a Coisa-em-si propriamente dita. Assim, "a contradição não é apenas um indicativo da imperfeição de nosso conhecimento, a limitação do conhecimento nos coloca em contato com a (limitação da) própria Coisa" (ZIZEK, 2012, p. 594). É por isso que Zizek insiste no fato de que Hegel é mais kantiano que o próprio Kant: desde o início, Kant já possuía o que procurava, mas era míope em decorrência de seu formalismo teórico; e o mérito de Hegel é ter encontrado uma gramática filosófica apropriada para radicalizar esse potencial

2 Mas ocorre que, no caso das antinomias da razão, é a própria perspectiva que é, em si, paraláctica, pois não se trata de uma mera mudança espacial no campo de visão, mas de um deslocamento entre dois níveis fundamentalmente assimétricos, isto é, entre a dimensão numênica e dimensão fenomênica da realidade.

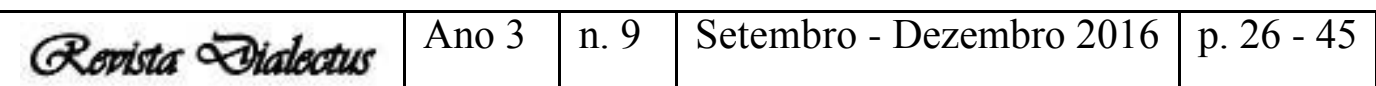


escondido em Kant. Desse modo, só podemos recuperar a dimensão ontológica pósreviravolta copernicana através de uma torção dialética radical: primeiramente temos o limite que me impede de ver a realidade "lá fora", em seguida temos a realidade como sendo esse próprio limite. Enquanto a paralaxe kantiana foca na limitação constitutiva do sujeito do conhecimento, que nos prende à eterna dicotomia sujeito/objeto, a paralaxe hegeliana é introduzida no próprio objeto, ou seja, a mudança aparente do objeto não diz respeito ao olhar sempre parcial de nosso ponto de perspectiva finito, mas consiste na diferença mínima contida na própria aparência do objeto. De nosso olhar fenomênico, um objeto nunca é exatamente aquilo que aparenta ser, ou seja, há sempre um desnível fundamental entre sua aparência e aquilo que ele é em si, por trás das aparências. Mas a questão é: e se aquilo que ele é em si for apenas uma ilusão de perspectiva, uma sombra projetada pela sua própria aparência? É aqui que o "em si” torna-se mera ilusão, ao passo que a aparência revela-se como sendo o próprio "em si" do objeto. De acordo com Zizek (2012), todo o esforço da dialética hegeliana é, portanto, pensar não propriamente a ontologia da aparência (uma análise fenomenológica do objeto), mas a própria ontologia como aparência, ou seja, a aparência enquanto pura aparência.

Nesse sentido, Hegel resolve dialeticamente o problema do formalismo kantiano, fundamentando a liberdade em sua real condição ontológica. Somos livres não em decorrência de nossa limitação constitutiva - enquanto houver uma lacuna que nos impeça de ver ou conhecer as causas que nos determinam -, mas somos livres porque a própria realidade é limitada em seu cerne, e isso nos garante a possibilidade de reconfigurar retroativamente as próprias coordenadas objetivas que nos determinam. Em outras palavras, se a realidade fosse plenamente constituída, nós seríamos então totalmente asfixiados em sua determinação ontológica a priori. Ainda que ignorássemos tais determinações (à maneira do formalismo transcendental), só o espectro de sua possibilidade já anularia o poder efetivo de nossa liberdade, tornando-a, em última instância, um mero pretexto cínico para a ação, mas desprovida de qualquer legitimidade conceitual. Portanto, a liberdade só é possível a partir de uma abertura ontológica mais originária.

A pergunta agora é: como então articular essa ideia de liberdade enquanto abertura ontológica com a ideia de subjetividade moderna? Aqui, o problema já é sua própria resposta: a ideia de sujeito moderno é a expressão mais pura dessa liberdade; ele 
surge justamente quando Kant faz explodir o fechamento ontológico da tradição mantendo as antinomias da razão como a condição de nossa finitude. Sujeito, ontologia (como paralaxe) e liberdade são, portanto, três conceitos que exprimem uma única e mesma ideia. Mas como reuni-los em uma só sentença? O desafio aqui consiste em pensar esses três elementos sem a exclusão de nenhum. O fato é que, ao longo de nossa tradição, fomos conduzidos a sacrificar sempre um deles, sem jamais conseguir pensar os três conjuntamente. Numa simples permutação, ou bem temos ontologia e liberdade, mas perdemos a concepção moderna de subjetividade (como a tradição estoica do amor fati), ou bem temos liberdade e sujeito, mas sacrifica-se a ontologia (como o idealismo transcendental de Kant). No entanto, a alternativa que une ontologia e sujeito não pode simplesmente excluir a noção de liberdade; é como se para um pensamento filosófico forte, a ideia de liberdade tivesse de ser incluída de alguma forma nessa série (do contrário seríamos alguma coisa como máquinas pensantes, ou, como temia Kant, um jogo de bonecos bem sincronizados, mas sem vida alguma). E é justamente essa alternativa que confere à liberdade seu significado mais próprio. Mas para isso, essa ontologia tem de ser compreendida como a própria fissura na realidade, que abre, por conseguinte, o espaço para pensar tanto da dimensão do sujeito moderno como a dimensão da autonomia humana.

\section{Subjetividade e Liberdade}

Mas é preciso dar um passo a mais nesse processo de radicalização do pensamento de Kant. Para isso, a atenção agora deve ser focada em sua segunda Crítica. Se Hegel rompe com seu formalismo transcendental, conduzindo as antinomias da razão pura a sua condição ontológica positiva, Lacan arrasta a filosofia moral de Kant a seu paroxismo, alcançando, assim, um limite ainda mais inaudito: a ideia de jouissance, um gozo para além do princípio do prazer, contida na própria forma de seu princípio moral ${ }^{4}$. O mote dessa estratégia reside numa estranha relação entre Kant e Sade, a partir da qual Lacan pôde revelar o núcleo obsceno e recalcado do formalismo moral kantiano. Nesse sentido, o propósito de se pensar Kant com Sade é, para Lacan (1963/1998), demonstrar

\footnotetext{
4 Importante aqui deixar claro que esse é um recorte epistemológico nosso. Não é que Zizek restrinja Hegel a uma leitura-limite da primeira Crítica kantiana, e Lacan à segunda. Conforme a própria análise de Zizek, a linha que separa um do outro é extremamente tênue. Se utilizamos essa divisão, é somente para esquematizar melhor o próprio pensamento de Zizek. Mas, para todos os efeitos, essa leitura satisfaz o nosso propósito, uma vez que se pode afirmar que um dos pontos de cisão entre Hegel de Lacan é de fato o conceito de jouissance.
} 
que na base do princípio formal da moral kantiana reside um gozo sádico silencioso. De que modo?

A ideia é basicamente a seguinte: quando Kant purifica o dever moral de todo conteúdo patológico, ou seja, dos desejos empíricos que corrompem a universalidade da Lei moral com inclinações idiossincráticas e utilitaristas, o resultado é o surgimento de uma vontade livre, totalmente desprovida de objeto, vinculada unicamente à pura forma da Lei. Segundo Lacan (1963/1998), o que Kant não percebe é que, nesse momento, quando se elimina do campo da universalidade moral todo objeto patológico em função de uma vontade livre que quer simplesmente a pura forma da Lei, ele automaticamente eleva essa própria forma da Lei moral à condição de um objeto inalcançável, impossível. Ou seja, ele não vê que a própria forma da Lei é o objeto par excellence do desejo, que impele uma depuração furiosa e compulsiva de todo conteúdo empírico que macula seu a priori transcendental. Então, na tentativa evacuar do domínio da Lei moral tudo o que possa manchar sua pureza formal, Kant promove uma destruição contínua e sistemática da própria realidade empírica.

Mas isso não é novidade, mesmo porque essa é base da crítica de Hegel (2003) contra Kant em sua análise sobre o Terror Revolucionário. A grande novidade lacaniana diz respeito ao gozo inerente a essa dinâmica, isto é, uma espécie de anomalia/protuberância produzida pela própria compulsão de purificação em nome da pura forma da Lei. É aqui que Sade (2009) cumpre um papel fundamental. A tese básica de Sade não é que nós devemos nos entregar aos nossos prazeres imediatos mais vulgares e assim gozar alegremente e sem obstáculos; o ponto de Sade é que o verdadeiro gozo só é possível através da lancinante experiência da dor, que surge ao exceder os limites do próprio prazer carnal. Nesse sentido, Sade também busca uma purificação do conteúdo patológico a fim de alcançar um gozo que se encontra para além do princípio do prazer. O elo que une Kant a Sade é, portanto, esse sentimento de dor, que se manifesta como sendo a única emoção transcendental possível: tanto Kant (2011a) como Sade (2009) almejam alcançar a universalidade (da Lei moral ou do gozo) submetendo, através de uma disciplina implacável, o princípio do prazer à dor da humilhação de nosso Eu patologizado. Desse modo, Sade revela o lado negativo e recalcado da moral kantiana: enquanto Kant proporciona a bela imagem do dever ético incondicional, Sade nos proporciona a imagem do corpo torturado como suporte material desse ideal de beleza. Em outras palavras, o desejo pela pura forma da Lei é o 
estrito correlato do gozo alcançado pelo corpo castigado.

O propósito de Zizek aqui é, portanto, enfatizar a referência objetal do sujeito transcendental kantiano. É claro que não podemos pensar esse correspondente objetal como um objeto empírico-fenomênico; devemos, antes, concebê-lo como a própria jouissance enquanto produto imanente do desejo quando vinculado à pura forma da Lei. Assim, o sujeito lacaniano deve ser pensado não apenas como sujeito transcendental (o sujeito barrado lacaniano - \$), mas estendido a seu correlato objetal, enquanto objeto pequeno $a$, que nada mais é do que o quadro vazio transcendental reificado na forma de gozo. Desse modo, $\$$ e $a$, a falta constitutiva do desejo e seu excesso de gozo correspondente, são a prioristicamente inconciliáveis - mas isso não porque são substâncias heterogêneas ou pelo fato de estarem distantes demais um do outro, e sim porque estão demasiadamente próximos, ou seja, trata-se de um só princípio separado por uma lacuna paraláctica. Devemos assim inverter ideia padrão de que o ser humano é eternamente insatisfeito porque deseja sempre o impossível, aquilo que está fora de seu alcance etc.; de acordo com a psicanálise, nosso desejo e nosso gozo coincidem, mas numa lógica invertida: gozamos sempre da impossibilidade constitutiva de realização de nossos desejos, ou seja, o gozo age somente na escala invertida do desejo. A relação aqui é novamente dialética: se por um lado, fracassamos em satisfazer nossos desejos, por outro, gozamos desse mesmo fracasso. Desse modo, a fórmula correta para essa relação entre desejo e gozo é $\$<a$ (a fórmula da fantasia lacaniana), que representa a eterna busca do sujeito pelo seu objeto de gozo. Mas a ênfase deve recair justamente no fato de que o gozo já foi obtido no fracasso de seu desejo, ou seja, a falta (do objeto) já é em si o próprio excesso (de gozo) gerado pela falta. Em outras palavras, o sujeito procura incessantemente sua completude objetal no campo fenomênico $(\mathrm{Eu}=\mathrm{Eu})$, contudo, posto que nenhum objeto fenomênico está à altura da dimensão transcendental, seu desejo é de antemão frustrado; ocorre que é justamente nessa frustração que incorre seu gozo. Portanto, não há aqui ponto de equilíbrio. Há somente falta e excesso: sua falta já é seu próprio excesso. E o sujeito é justamente essa tensão interna entre a falta constitutiva do desejo e seu gozo obsceno recalcado, ou conforme a álgebra lacaniana: $\$<>a$.

Significa, com isso, que estamos condenados eternamente ao paradoxo de Kant com Sade, ou seja, a essa repetição demoníaca entre desejo/frustração e gozo? Em outros termos, estamos condenados a gozar na dor e na humilhação de nosso fracasso?

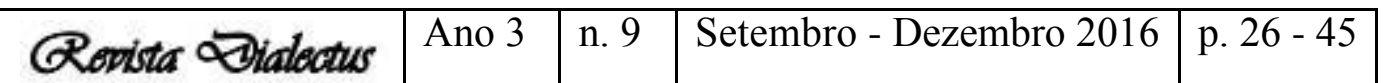


A resposta é não. Mas é preciso aqui novamente realizar o passo que Kant se recusou a dar. Para Zizek (1999), Sade não representa a verdade, mas o sintoma de Kant. Ou seja, Sade representa a acomodação de Kant, o preço por ter evitado as consequências éticas de sua própria descoberta, por ter medo de ir até o fim em sua intuição original. Desse modo, não cabe salvar Kant suavizando o rigor de seu imperativo categórico, abrindo certas concessões à esfera patológica do desejo etc., mas, pelo contrário, cumpre dar um passo a frente e sermos ainda mais radical que Kant: devemos sacrificar não apenas os objetos empíricos que contaminam a pureza da universalidade moral, mas sacrificar também o gozo incutido na própria lógica do sacrifício.

De modo mais detalhado: primeiramente, a moral kantiana nos impele a sacrificar tudo em nome da pura forma da Lei; porém, como vimos, Lacan percebeu com muita perspicácia que essa dinâmica assemelha-se estranhamente à maneira como Sade descreve o modo do gozo purificado através do açoite infatigavelmente do corpo da vítima; assim, a saída para esse impasse é justamente abdicar do lugar de gozo através de uma destituição radical não só do conteúdo patológico de nosso eu fenomênico, mas do próprio quadro transcendental que sustenta nossa identidade. A verdadeira liberdade consiste, portanto, na destituição completa de nosso gozo narcísico gerado pela lei do sacrifício. Em suma, cabe consumar o sacrifício derradeiro: o sacrifício do próprio sacrifício. E a nossa hipótese mais básica é a de que Kant sabia isso desde sempre, mas para manter-se fiel ao seu a priori formal, ele não teve como abdicar do lado negro da medalha, de seu gozo obsceno. Nosso intuito, portanto, não é condenar, mas salvar Kant: ao desatar o nó sádico de seu pensamento, abrimos com isso uma nova possibilidade de se pensar Kant sem Sade.

\section{Política e Emancipação}

Por fim, cumpre perguntar como transpor essa mesma destituição radical do $a$ priori formal para o campo da política. Ou seja, a questão fundamental agora é pensar uma real política emancipatória.

Com o esgotamento das forças utópicas que animaram a conturbada história do século XX, entramos definitivamente no que Zizek (2002) denomina de era da póspolítica, momento histórico em cujo contexto a política perde completamente seu potencial emancipatório e é, por conseguinte, reduzida a um mero jogo administrativo, a uma espécie de gestão de negócios burocráticos. O problema é que esse estado anêmico

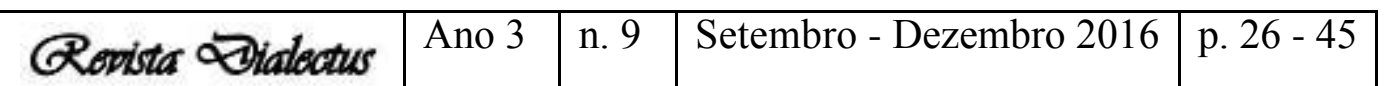


pós-ideológico produz a triste impressão de que enfim chegamos ao estágio final da história (como bem expressa o título da obra de Francis Fukuyama (1992): O fim da história e o último homem) e que toda luta política engajada e fundada em valores universais nada mais é que um anacronismo sem sentido. Aqui fazem eco as palavras de Winston Churchill, para quem a democracia é o melhor dentre os piores dos regimes políticos já existentes. Ou seja, a premissa pós-ideológica básica de nossos dias é que a humanidade finalmente atingiu sua maioridade política com a forma de democracia neoliberal, e se ela permanece incompleta e cheia de lacunas, esse é um ponto positivo, pois é sua própria limitação inerente que nos permite reconhecer nela a sua condição finita e secular. Desse modo, voltar a acreditar em ideais utópicos é, como dizem os neoliberais esclarecidos, voltar a brincar como crianças e sonhar com contos de fadas. Estamos, portanto, com os pés fincados na realidade em sua forma efetiva, livres de devaneios e quimeras utópicas. Mas aqui devemos aplicar uma torção dialética fundamental: e se esse posicionamento pós-ideológico for exatamente a forma da ideologia stricto sensu? Nesse sentido, a ideologia "parece surgir exatamente quando tentamos evitá-la e deixa de aparecer onde claramente se esperaria que existisse”, ou seja, "quando um processo é denunciado como 'ideológico por excelência', pode-se ter certeza de que seu inverso não é menos ideológico" (ZIZEK, 2010, p. 9). Assim, nada mais ideológico do que a ideia de uma era pós-ideológica: "o paradoxo é que a saída da(quilo que vivenciamos como) é a própria forma de nossa escravização a ela" (ZIZEK, 2010, p. 12). Desse modo, a conclusão é que, longe de ser um processo natural de amadurecimento político, devemos considerar o princípio formal da democracia neoliberal como o regime que melhor se adequa ao funcionamento dinâmico do capitalismo tardio.

Portanto, para sustentar uma crítica da ideologia nos dias de hoje é preciso retomar com urgência o velho conceito marxista de luta de classes. No entanto, a dinâmica de funcionamento do capitalismo na sua forma tardia não permite mais que esse conceito seja utilizado em sua forma padrão, ortodoxa. O ponto é que o capitalismo tardio se apresenta de forma extremamente paradoxal, como um sistema econômico em constante autorrevolução. Ou seja, segundo Zizek (2012), é praticamente impossível combater o capitalismo se posicionando de frente a ele, como se ele fosse um inimigo visível e identificável. Sua astúcia consiste precisamente em subverter sua própria crise em força autopropulsora. Em outras palavras, é como se no momento em que 
identificamos o inimigo externo, prontos para confrontá-lo diretamente, fossemos subrepticiamente envolvidos em sua lógica dominante. Por essa razão, não é mais possível pensar o conceito de luta de classes segundo a oposição básica do NÓS contra ELES. Em nossa dita era pós-ideológica, somos completamente envolvidos num processo perturbador no qual o próprio inimigo é quem oferece as armas para o combate, nos deixando, desse modo, completamente a mercê de sua atividade alienante. E eis a grande dificuldade dos nossos tempos: como combater um inimigo que age exatamente contra aquilo que ele parece ser? Em outras palavras: como ser revolucionário diante de um sistema que já é a própria revolução encarnada? Ou, reproduzindo o próprio Zizek (2011a): “Como, então, podemos revolucionar uma ordem cujo próprio princípio é a sua constante autorrevolução? Talvez seja essa $a$ questão atual” (p. 296).

O primeiro passo para sair desse impasse é rejeitar o historicismo vulgar que dominou o pensamento pós-metafísico de nossos tempos. O que perdemos com a total horizontalidade do pensamento pós-moderno foi exatamente o ponto sincrônico (o eixo vertical) que organiza e fundamenta a diacronicidade (o eixo horizontal) do tempo. É claro que para recuperar a veia crítica do pensamento, precisamos, mais do que nunca, reestabelecer esse eixo da sincronicidade histórica, ou seja, recuperar o núcleo ahistórico da própria história que sintetiza o fluxo dos acontecimentos em um campo de sentido (em termos kantianos, isso corresponderia ao sujeito da apercepção transcendental; em termos lacanianos, ao Significante-Mestre, o $\mathrm{S}_{1}$ ). No entanto, o problema que se coloca é como repensar essa sincronicidade do tempo (o eterno aquiagora) sem sucumbir à armadilha do platonismo, isto é, sem ser surpreendido por uma metafísica da presença centrada em torno de um sentido hegemônico, oniabrangente. A resposta, Zizek vai encontrar na concepção paradoxal de Walter Benjamin de um materialismo teológico.

O mérito de Benjamin consistiu em ter inserido no seio do marxismo uma inflexão teológica, sem a qual o próprio materialismo histórico torna-se ineficiente. E é exatamente isso que nos permitirá recuperar o verdadeiro sentido de luta de classes, para além da noção vulgar de conflito de interesses entre dois (ou mais) grupos no interior de uma mesma sociedade. A tese fundamental do materialismo teológico é basicamente que não podemos conceber a história de maneira ingênua, como um plano neutro em cujo espaço se trava lutas e conflitos. Para Benjamin (1996), a história é essencialmente uma narrativa tendenciosa, contada sempre do ponto de vista dos vencedores. Não cabe, 
porém, aplicar aqui o mote nietzschiano da vontade de poder, em que o mais forte tem direito de impor sua perspectiva sobre o mais fraco etc. A luta de classe para Benjamin (1996) não é uma luta simétrica entre dois grupos antagônicos. A finesse da argumentação benjaminiana é que a luta se trava em dois planos fundamentalmente assimétricos, que correspondem, por sua vez, a duas formas distintas de tempo: o tempo vazio/homogêneo (o tempo linear contado pelos vencedores) e o tempo cheio (o tempo saturado de agoras, do eco das vozes abafadas e sucumbidas). Nesse sentido, a história enquanto um campo formal a priori, como um receptáculo neutro a partir do qual vão se inscrevendo os acontecimentos na linha cronológica do tempo, é infamemente fundada sobre o silêncio dos oprimidos, que, por sua vez, corta diagonalmente todo o campo da narrativa hegemônica. Desse modo, a teologia de Benjamin não é nada mais do que esse núcleo recalcado da história que aspira por redenção. O cerne da revolução não está, portanto, no futuro, como alega a tese do evolucionismo histórico; a verdadeira revolução é teológico-materialista, isto é, realizada no salto de tigre em direção ao passado, regatando a potencialidade oculta de um passado não histórico - ou melhor, ahistórico - que pulsa silenciosamente e que ainda precisa ser efetivado.

Desse modo, compreendemos que os conflitos no interior da história são conflitos articulados pela própria classe dominante, isto é, a burguesia. A divisão de classes é, portanto, uma necessidade estrutural da sociedade burguesa, uma vez que ela só pode sobreviver como ideal de reconciliação. Assim, a classe oprimida satisfaz as necessidades da burguesia assumindo a forma de um obstáculo que projeta num horizonte infinito a harmonia das classes. Mas se é o próprio obstáculo que sustenta a fantasia ideológica da burguesia, então, no momento em que ele for suprimido, todo o edifício social desaba. Nesse sentido, todo apelo social burguês, que vise uma integração harmônica da sociedade como um todo, é profundamente ideológico: o obstáculo é sempre a priori, constituinte da própria visão de mundo burguês. E eis a razão pela qual a burguesia é essencialmente sadomasoquista: ela goza compulsivamente do seu próprio fracasso, adiando para sempre o momento de reconciliação final. Nesse sentido, a saída para uma verdadeira política da reconciliação só é possível através de um ato político, quando a classe oprimida assume a posição de proletariado, isto é, identifica-se com a verdadeira universalidade. O proletariado seria, então, a verdade da própria burguesia, seu núcleo recalcado. No entanto, para Zizek (2011b), essa mudança de posição é puramente paraláctica, não havendo nenhuma 
necessidade de derramamento de sangue.

A proposta política de Zizek (2011b) não consiste de modo algum em implementar o terror revolucionário, na tomada incessante de poder, ou em promover a autorrevolução incessante. Para o filósofo, esse movimento corresponderia justamente ao modus operandi específico do capitalismo avançado. E nesse sentido já não cabe mais resistir lutando; a luta já é antecipadamente vencida pelo inimigo. Então, o que fazer? Nesse caso, o melhor é não fazer nada, ou melhor, fazer o nada, seguindo o exemplo de Bartleby (personagem do romance de Herman Melville), que, em sua disciplinada recusa (seu célebre prefiro não fazê-lo), mais do que realizar uma destruição de todo conteúdo positivo, infundindo o terror da terra arrasada, ele abre o puro vazio positivo, a negação determinada, a partir da qual a verdadeira alteridade, um pensamento radicalmente novo, pode advir. Esse espaço em branco, determinado, nada mais é do que o verdadeiro campo da reflexividade, que é a própria subjetividade.

Por isso que Zizek (2015), em um artigo recentemente publicado sobre o atentado terrorista ao Charlie Hebdo, diz com todas as letras que o principal a fazer agora não é (re)agir aos acontecimentos, mas pensar, abrir um novo espaço para o pensamento, um pensamento para além das coordenadas padrões de nossa política existente. Em uma palavra, cumpre subjetivar a própria esfera objetiva que nos subjetiva (ou aliena). A verdadeira liberdade é, portanto, não (somente) a liberdade de expressão, como reza nossa ideologia democrática liberal, mas (fundamentalmente) a liberdade de pensamento, de pensar o impensável, de arriscar o impossível.

\section{Referências:}

BENJAMIN, W. Sobre o conceito da história. In: BEIJAMIN, W. Obras escolhidas. Magia e Técnica, Arte e Política: ensaios sobre literatura e história da cultura. São Paulo: Brasiliense. 1996.

FUKUYAMA, F. The End of History and the Last Man. New York: Free Prees, 1992.

GRAY, J. As visões violentas de Zizek. Revista Piauí, São Paulo, 71. ed., ago 2012. p. 68. Disponível em: <http://revistapiaui.estadao.com.br/materia/as-visoes-violentas-dezizek/>.Acessado em: 12 mar 2013.

HABERMAS, J. O Futuro da Natureza Humana: A caminho de uma eugenia liberal? São Paulo: Martins Fontes, 2010.

\begin{tabular}{|c|c|c|c|}
\hline Qovista Dialectus & Ano 3 & n. 9 & Setembro - Dezembro 2016 \\
\hline
\end{tabular}


HEGEL, W.G.F. Fenomenologia do Espírito. Rio de Janeiro: Vozes, 2003.

KANT. I. Textos Selectos. Rio de Janeiro: Vozes. 2005.

. Crítica da Razão Pura. Lisboa: Fundação Calouste Gulbenkian, 2010.

. Crítica da Razão Prática. São Paulo: Martins fontes, 2011.

LACAN, J. (1963) Kant com Sade. IN: LACAN, J. Escritos. Rio de Janeiro: Jorge Zahar, 1998. pp. 776-803.

SADE, M. Filosofia na Alcova. São Paulo: Iluminuras, 2009.

SCHNEEWIND, J.B. A invenção da autonomia. São Leopoldo: Unisinos, 2005.

ZIZEK, S. Kant with (or against) Sade. IN: WRIGHT, E.; WRIGHT, E.(ed.). The Zizek Reader. Oxford: Blackwell Publishers Ltd., 1999. pp. 281-301.

. Le Spectre Rôde Toujours. Actualité du Manifeste du Parti Communiste. Paris: Nautilus, 2002.

. A visão em paralaxe. São Paulo: Boitempo, 2008.

- Introdução: O espectro da ideologia. In: ŽIŽEK, S. (org). Um Mapa da ideologia, Rio de Janeiro: Contraponto, 2010, pp. 07-38.

. Órgãos sem Corpo: Deleuze e Conseqüencias. Rio de Janeiro: Cia. de Freud, 2011a.

. Em defesa das causas perdidas. São Paulo: Boitempo, 2011 b.

. Menos que Nada: Hegel e a sombra do materialismo dialético. São Paulo: Boitempo, 2012.

- Absolute Recoil: Toward a New Foundation of Dialectic Materialism. London/New York: Verso, 2014.

. on the Charlie Hebdo massacre: Are the worst really full of passionate intensity? Newstatesman, London, 10 jan de 2015. Disponível em: $<$ http://www.newstatesman.com/world-affairs/2015/01/slavoj-i-ek-charlie-hebdomassacre-are-worst-really-full-passionate-intensity $>$. Acessado em: 12 jan 2015 